\title{
Rethinking the Liquidity Puzzle: Application of a New Measure of the Economic Money Stock
}

\author{
Logan J. Kelly ${ }^{a}$, William A. Barnett ${ }^{b}$, and John W. Keating ${ }^{c}$ \\ ${ }^{a}$ Bryant University, Department of Economics, Smithfield, RI 02917 \\ e-mail: lkelly@bryant.edu Ph: (401) 232-6897 Fax: (401) 232-6319 \\ ${ }^{\boldsymbol{b}}$ University of Kansas, Department of Economics, Lawrence, KS 66045 \\ e-mail: barnett@ku.edu Ph: (785) 864-2844 Fax: (785) 864-5760 \\ ${ }^{c}$ University of Kansas, Department of Economics, Lawrence, KS 66045 \\ e-mail: jkeating@ku.edu Ph: (785) 864-2837 Fax: (785) 864-5270
}

April 2010

\begin{abstract}
Historically, attempts to solve the liquidity puzzle have focused on narrowly defined monetary aggregates, such as non-borrowed reserves, the monetary base, or M1. Many of these efforts have failed to find a short-term negative correlation between interest rates and monetary policy innovations. More recent research uses sophisticated macroeconomic and econometric modeling. However, little research has investigated the role measurement error plays in the liquidity puzzle, since in nearly every case, work investigating the liquidity puzzle has used one of the official monetary aggregates, which have been shown to exhibit significant measurement error. This paper examines the role that measurement error plays in the liquidity puzzle by (i) providing a theoretical framework explaining how the official simple-sum methodology can lead to a liquidity puzzle, and (ii) testing for the liquidity effect by estimating an unrestricted VAR.
\end{abstract}

Key words: Liquidity Puzzle, Monetary Policy, Monetary Aggregation, Money Stock, Divisia Index Numbers

JEL classification codes: E50; E43 


\section{Introduction}

The liquidity puzzle is defined to be the failure of monetary policy disturbances to create negative short-run correlations between nominal interest rates and the money stock. That puzzle has been a persistent thorn in empirical monetary economics research. The absence of a liquidity effect appears in Melvin (1983), Christiano (1991), and Leeper and Gordon (1992), among many others.

Historically, attempts to solve the liquidity puzzle have focused on narrowly defined monetary aggregates, such as non-borrowed reserves, the monetary base, or M1 (see, e.g., Strongin 1995 and Christiano, Eichenbaum and Evens 1996). Many of these efforts have failed to find a short-term negative correlation between interest rates and monetary policy innovations. Table 1 surveys data used and methodology found in previous studies. More recent research uses sophisticated macroeconomic and econometric modeling. Keen (2004), for example, develops a dynamic stochastic general equilibrium model with sticky prices and financial market frictions, and Bernanke, Boivin and Eliasz (2005) utilize a factor augmented VAR which, rather than using a monetary aggregate, estimates unobserved factors. But little research has investigated the role measurement error plays in the liquidity puzzle; In nearly every case, work investigating the liquidity puzzle has used one of the official monetary 
aggregates, which have been shown by Barnett (1980) and others to exhibit significant measurement error.

Table 1: Summary of data and methodology used in empirical studies of the liquidity puzzle

\begin{tabular}{lcccc}
\hline \hline Author (Year) & $\begin{array}{c}\text { Monetary } \\
\text { Aggregate }^{\mathrm{a}}\end{array}$ & $\begin{array}{c}\text { Interest }^{\mathrm{b}} \\
\text { Rate }\end{array}$ & $\begin{array}{c}\text { Other }^{\mathrm{c}} \\
\text { Variables }\end{array}$ & $\begin{array}{c}\text { Model }^{\mathrm{d}} \\
\text { Type }\end{array}$ \\
\hline Mishkin (1982) & M1, M2 & TB3 & $\begin{array}{c}\text { IP, CPI, U, } \\
\text { BOP }\end{array}$ & Single \\
Reichenstein (1987) & M1 & TB3 & IP, CPI, U & Single \\
Cochrane (1989) & NBR & TB3 & & Filter \\
Leeper and Gordon (1992) & M0, M1, M2 & FF & IP, CPI & Single \\
Sims (1992) & M1 & FF & & VAR \\
Eichenbaum and Evens (1995) & M0, M1, NBR & FF & IP, CPI & VAR \\
Strongin (1995) & TR, NBR & FF & IP, CPI & VAR \\
Christiano et al. (1996) & NBR & FF & & VAR \\
Serletis and Chwee (1997) & M0, M1, M2, M3, & FF & IP, CPI, CP & VAR \\
Hamilton (1997) & L, MSI & FF & & Single \\
Bernanke et al. (2005) & NBR & FF & & F-VAR \\
\hline
\end{tabular}

${ }^{\mathrm{a}} \mathrm{M} 0$ is the monetary base. $\mathrm{M} 1, \mathrm{M} 2, \mathrm{M} 3$, and $\mathrm{L}$ are official simple sum monetary aggregates. NBR is non-borrowed reserves, and TR is total reserves. MSI refers to Divisia money.

${ }^{b}$ FF is the effective federal funds rate. TB3 is the 90 day Treasury bill rate.

${ }^{c} \mathrm{IP}$ is industrial production. $\mathrm{CPI}$ is the consumer price index. $\mathrm{U}$ is the unemployment rate. $\mathrm{BOP}$ is the balance of payments.

The measurement problems with the official narrow money aggregates stem from two sources: first, narrow monetary aggregates ignore the monetary services of monetary assets not included; second, significant measurement error from the use of inferior simple sum methodology exists, even with narrow 
monetary aggregates. ${ }^{1}$ In this paper, we examine the role that measurement error plays in the liquidity puzzle by using monetary aggregates, including a new measure of money, which do not suffer from the aforementioned defects. We provide a theoretical framework, based on Kelly (2009), explaining how the simple sum methodology can lead to a liquidity puzzle and test for the liquidity effect by estimating an unrestricted VAR.

We chose sub-sample periods and econometric methods to replicate previous studies. In particular, we follow Strongin (1995) who provides excellent historical justification for selecting sub-sample periods. Our results show that in the United States, when the current economic stock of money, as defined by Kelly (2010), is used as the monetary variable, a liquidity effect is observed in all sub-periods and is significant at the 95 percent confidence level in the full sample and the $1982-2006$ and $1994-2006$ sub-periods. Moreover, analysis of the variance decomposition of VAR's estimated with various monetary aggregates suggest that broader monetary aggregates have more explanatory power over the effective federal funds rate, and that broader aggregates, when measured using reputable index numbers, do a better job of eliminating the liquidity puzzle than do narrow aggregates. This result is

${ }^{1}$ There is a long literature, beginning with Hutt (1963), establishing the inferiority of simple sum monetary aggregation. For a summary of this literature, see section 2.3. 
surprising given that the conventional wisdom for solving the liquidity puzzle has been to use narrow monetary aggregates.

The remainder of this paper proceeds as follows. Section 2 gives a brief discussion of the measurement problems with the existing narrow money aggregates. Section 3 discusses the data that we will be using and explains the justification for the sample and sub-sample periods. Section 4 tests for the liquidity effect exhibited by various monetary variables by estimating an unrestricted VAR including price and output. Section 5 concludes.

\section{Problems with the Current Measures of Narrow Money}

A traditional approach to solving the liquidity puzzle has been to focus on narrow monetary aggregates, such as non-borrowed reserves, the monetary base, or M1. There exist significant measurement errors even in these narrow monetary aggregates. These include accounting errors in the reporting of nonborrowed reserves, distortion caused by retail sweeps, and aggregation error resulting from the use of inferior simple sum methodology.

\section{$2.1 \quad$ Non-Borrowed Reserves}

Using non-borrowed reserves as the monetary quantity aggregate has been a common approach to focusing on narrowly defined money. See, for example, Serletis and Chwee (1997), who considers a non-borrowed-monetary-base VAR 
to resolve the liquidity puzzle (See also Strongin (1995) and Christiano et al. (1996)).

This approach is not without disadvantages, however. Recent events in monetary history, from 2006 through 2009, have raised serious questions about the quality of non-borrowed reserve data in the U.S. case. Figure 1 displays nonborrowed reserves from January 2005 to February 2010, as published by the Federal Reserve Board of Governors. Note that from January 2008 through November 2008, non-borrowed reserves are negative, indicating that borrowed reserves exceeded total reserves. In other words, if Figure 1 is correct, equilibrium quantity of reserves borrowed exceeded the total equilibrium quantity of reserves supplied, which is a contradiction. Barnett and Chauvet (2009) explain that this inconsistency results from the improper inclusion of Term Auction Facility borrowing from the Federal Reserve in borrowed reserves, regardless of whether or not held as reserves. 


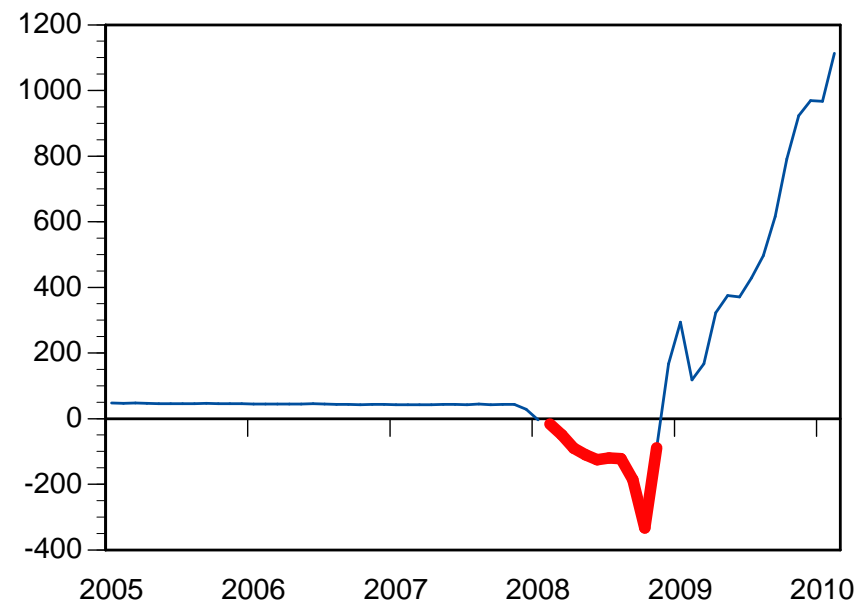

Figure 1: Non-Borrowed Reserves of Depository Institutions

\subsection{Retail Sweeps}

Retail sweeps are an accounting trick that allows depository institutions to reduce required reserves by temporarily transferring funds out of their customers' checkable deposit accounts into money market deposit accounts (MMDAs), which have no statutory reserve requirement, while continuing to service the accounts as demand deposit accounts. See, e.g., Anderson and Rasche (2000). Dutkowsky and Cynamon (2003) demonstrate how this practice has substantially distorted the growth of traditional measures of narrow money, including M1, total reserves, and the monetary base. ${ }^{2}$

${ }^{2}$ See also Alan Greenspan's Testimony, "Monetary Policy Report to the Congress," Federal Reserve Bulletin, August 1995, pp. 772-3 
As Anderson and Rasche (2000) point out, retail sweeps are invisible to the customer. Thus it is unlikely, barring competitive pressure, that depository institutions will pass on interest earned on these funds to the consumer. Moreover, from the consumers' perspective, checkable deposit account services remain unchanged. Hence, the official M1 aggregate is understated.

The effect on M2 is somewhat less, because MMDA's are included in M2; thus the official M2 aggregate published by the Federal Reserve Board of Governors is unaffected by sweeps. However, aggregation theoretic monetary aggregates, such as the Divisia quantity aggregates are affected, since they correctly recognize that the services provided by demand deposits are not identical to those produce by properly serviced MMDA's.

\subsection{Problems with Simple Sum Monetary Aggregates}

Barnett and others have long argued that the use of simple sum monetary aggregates is theoretically indefensible in a modern economy. ${ }^{3}$ Barnett (1980) proved that simple sum monetary aggregation can only be justified in theory when all monetary assets, including currency, yield the same own rate of interest; and in that paper he began the modern theory of economic monetary aggregation with the derivation of the user cost of money and the Divisia and

${ }^{3}$ See, e.g., Barnett (1980), Barnett and Serletis (2000), Barnett et al. (2005), Barnett et al. (2008), Barnett and Chauvet (2009), Kelly (2009), and Kelly (2010). 
Fisher Ideal monetary aggregates. Barnett, Chae, and Keating (2005) demonstrated that simple sum aggregates often exhibit significant upward bias. Kelly (2009) demonstrated that simple sum monetary aggregates fail to capture much of the dynamics between interest rates and the money stock. We will review the argument presented by Kelly (2009) in this sub-section.

\subsubsection{Definition of the Current Stock of Money}

Following Barnett (1991), we define the economic stock of money (ESM) as the present value of current and future monetary service flows. Barnett, Keating and Kelly (2008) and Barnett et al. (2005) formulate ESM under uncertainty as

$$
E S M_{t}=E_{t}\left[\sum_{s=t}^{\infty}\left(\Gamma_{s} \sum_{n=1}^{N} m_{n s} \psi_{n s}\right)\right],
$$

where

$$
\Gamma_{s}=\beta^{s-t} \frac{\partial u}{\partial C_{s}} / \frac{\partial u}{\partial C_{t}}
$$

is the subjectively-discounted marginal rate of intertemporal substitution between $C_{t}$, consumption in the current period $t$, and $C_{s}$, consumption in the 
future period $s .{ }^{4}$ There are $N$ monetary assets, $m_{n t}$ is the quantity of monetary asset $n$ held in period $t$ and $\psi_{n t}$ is the user cost price of monetary asset $n$ held in period $t .^{5}$

Kelly (2010) showed that the ESM can be decomposed into two stocks by defining

$$
\tilde{m}_{n, t+j}=\left\{\begin{array}{ll}
0 & \text { if } j=0 \\
\sum_{i=1}^{j} \Delta m_{n, t+i} & \text { if } j>0
\end{array} .\right.
$$

Then noting that

$$
m_{n s}=m_{n t}+\tilde{m}_{n s} \forall s \geq t
$$

and substituting (4) into (1), he got

$$
E S M_{t}=E_{t}\left(\sum_{s=t}^{\infty} \Gamma_{s} \sum_{n=1}^{N} m_{n t} \psi_{n s}\right)+E_{t}\left(\sum_{s=t}^{\infty} \Gamma_{s} \sum_{n=1}^{N} \tilde{m}_{n s} \psi_{n s}\right) .
$$

4 The representative consumer's current period intertemporal utility function, $u_{t}$, is a standard utility function containing monetary assets. It is assumed to be blockwise weakly separable in each period's consumption of goods and monetary assets. Note that it is not an elementary utility function in good alone, since it contains monetary assets. It is the derived utility function that exists if money has positive value in equilibrium. See Arrow and Hahn (1971) for proof of the existence of the derived utility function.

${ }^{5}$ The user cost, $\psi_{n t}$, used here is the user cost under risk neutrality derived by Barnett (1995) and Barnett et al. (1997). It is formulated as

$$
\psi_{n t}=\frac{E_{t} R_{t}-E_{t} r_{n t}}{1+E_{t} R_{t}} .
$$

See Barnett and Serletis (2000) for further relevant reference on monetary aggregation under risk. 
Kelly (2010) named the first double summation the current stock of money (CSM), which can be interpreted to be the stock of currency needed to provide the monetary service flow equivalent to that of the contemporaneous monetary portfolio, excluding expected future changes in the portfolio allocation.

Consider the following assumptions:

1. The expectation of the stochastic discount factor in time period $t$ is

$$
E_{t}\left(\Gamma_{s}\right)=\prod_{u=t}^{s}\left[1+E_{t}\left(R_{u}\right)\right]^{-1}
$$

2. the benchmark rate follows a martingale process, so that $E_{t}\left(R_{s}\right)=R_{t}$ for all $s \geq t$,

3. $\operatorname{cov}\left(\sum_{n=1}^{N} m_{n t} \psi_{n s}, \Gamma\right)=0$,

4. and $\psi_{n s}$ follows a martingale process $\forall n=1 \ldots N$.

Kelly (2010) showed under those assumptions that the current stock of money, CSM, reduces to the currency equivalent index (Rotemberg, Driscoll, and Poterba (1995)),

$$
C S M_{t}=\sum_{n=1}^{N} \frac{R_{t}-r_{n t}}{R_{t}} m_{n t}
$$

where $R_{t}$ is the rate of return on the benchmark asset in period $t$ and $r_{n t}$ is the rate of return yielded by monetary asset $n$ in period $t$. Barnett (1991) 
previously showed that the $\mathrm{CE}$ index is a special case of the discounted present value of the Divisia monetary service flow.

\subsubsection{Definition of the Investment Stock of Money}

We define the investment stock of money (ISM) in time period $t$ to be the discounted present value of the return yielded by the portfolio of monetary assets held during time period $t$. Kelly (2009) derives the ISM, through a direct application of asset pricing theory, to be

$$
I S M_{t}=E_{t}\left[\sum_{s=t}^{\infty}\left(\Gamma_{s} \sum_{n=1}^{N} m_{n t} r_{n s}\right)\right],
$$

where $\Gamma_{s}$ is the subjectively-discounted marginal rate of intertemporal substitution between consumption in the current period $t$ and the future period $s, m_{n t}$ is the quantity of monetary asset $n$ held in period $t$, and $r_{n t}$ is the return yielded by monetary asset $n$ held in period $t$.

Now consider the following assumptions:

1. The expectation of the stochastic discount factor in time period t is

$$
E_{t}\left(\Gamma_{s}\right)=\prod_{u=t}^{s}\left[1+E_{t}\left(R_{u}\right)\right]^{-1}
$$

2. the benchmark rate follows a martingale process, so that $E_{t}\left(R_{s}\right)=R_{t}$ for all $s \geq t$, 
3. $\operatorname{cov}\left(\sum_{n=1}^{N} m_{n t} r_{n s}, \Gamma\right)=0$,

4. and $r_{n s}$ follows a martingale process $\forall n=1 \ldots N$.

Kelly (2009) showed under those assumptions that (7) reduces to

$$
I S M_{t}=\sum_{n=1}^{N} \frac{r_{n t}}{R_{t}} m_{n t}
$$

\subsubsection{Decomposition of the Simple Sum Monetary Aggregates}

Combining (6) and (8) yields

$$
C S M_{t}+I S M_{t}=\sum_{n=1}^{N} \frac{R_{t}-r_{n t}}{R_{t}} m_{n t}+\sum_{n=1}^{N} \frac{r_{n t}}{R_{t}} m_{n t}=\sum_{n=1}^{N} m_{n t}
$$

where $\sum_{n=1}^{N} m_{n t}$ is the simple sum monetary aggregate (SSUM). Hence, the SSUM confounds together CSM and ISM. $^{6}$ Kelly (2009) studies this confounding by examining the first derivative of each with respect to the return yielded by each monetary asset:

$$
\frac{\partial}{\partial r_{n t}} C S M=-\frac{m_{n t}}{R_{t}} \quad \forall n=1 \ldots N
$$

${ }^{6}$ See Barnett et al. (2005), Barnett et al. (2008), and Kelly (2009) for further discussion of how simple sum monetary aggregates confound the monetary and investment functions of monetary assets. 


$$
\frac{\partial}{\partial r_{n t}} I S M=\frac{m_{n t}}{R_{t}} \quad \forall n=1 \ldots N
$$

Note that (10) and (11) are identical, except that they have opposite signs. Moreover, Kelly (2009) showed that the first difference of CSM and the first

difference of ISM are strongly negatively correlated. Since $r_{n t}$ is a function of interest rates, equations (9), (10) and (11) make it clear that the simple sum monetary aggregates fail to capture the true relationship between the economic money stock and interest rates. Thus, theory predicts that when simple sum aggregation is used, a liquidity puzzle is a likely outcome.

\section{Preliminaries Concerning Data}

\subsection{Data Selection}

We chose variables to replicate the analysis of Leeper and Gordon (1992), with the exception of the monetary aggregates chosen and the use of core PCE. Variables and transformations used are as follows:

FEDF is the first difference of the effective Federal Funds Rate;

CSM is the log change of the Current Stock of Money seasonally adjusted measured by the Currency Equivalent Index (See Rotemberg et al., 1995 and Kelly 2010);

NBR is the log change of non-borrowed reserves; 
PCE is the log change of the personal consumption expenditures price deflator , excluding seasonally adjusted food and energy, as excluded by the Federal Reserve to focus on long run inflation ;

IP is the log change of the industrial production index seasonally adjusted.

\subsection{Sample and Sub-sample Period Selection}

We analyze monthly data from January 1979 through June 2006, which we divide into three sub-periods based on the operating regime history of the Federal Reserve. Strongin (1995) gives excellent support for this subdivision, which we repeat here:

1979 - 1982: Non-borrowed reserves targeting. This sub-period corresponds roughly to the episode in monetary history known as the monetarist experiment. Short-run money growth targets were set at each FOMC meeting, and then non-borrowed reserves targets were calculated based on those money growth targets.

1982 - 2006: Borrowed reserves/Federal funds targeting. During this subperiod, the Federal Reserve abandoned setting short-run money growth targets in favor of using the Federal Funds rate as an operational intermediate target.

1994 - 2006: The Federal Reserve Board permitted the use of Retail Sweeps. In 1994, the Federal Reserve allowed the use of retail sweeps, which were shown by Dutkowsky and Cynamon (2003) to distort the growth of 
traditional measures of narrow money. This distortion has led to a significant literature on the effects of sweeps.

These sub-periods are roughly equivalent to sub-periods used by Leeper and Gordon (1992). The 1994 - 2006 sub-period is not used in either Strongin (1995) or Leeper and Gordon (1992); however, given the impact of retail sweeps on narrow money, 1994 - 2006 is a natural sub-period to investigate.

\section{Evidence from the VAR}

\subsection{Identification}

We begin our empirical analysis by following Leeper and Gordon (1992) in estimating a VAR including money growth, FEDF, PCE and IP. Let

$$
Z_{t}=\left(\rho_{t}, F E D F_{t}, P C E_{t}, I P_{t}\right)^{\prime}
$$

be the vector of variables for which we estimate

$$
Z_{t}=A+B(L) Z_{t-1}+u_{t}, \quad u_{t} \sim N(0, \Sigma),
$$

where $\rho_{t}$ is a measure of the log change of the money stock. The system is fully unrestricted, so lags of all four variables are allowed to predict money growth. Leeper and Gordon point out that this system has a long history in the literature, having been studied extensively by Sims (1980) and Litterman and Weiss (1985), among others, before Leeper and Gordon (1992). 
We estimate a separate VAR for NBR and CSM at the M1, M2 and M3 levels of aggregation for the full sample and each sub-sample. The Akaike information criterion is used to select lag length for each VAR estimated. Table 2 reports lag length selected for each VAR.

Table 2: Lag length selection.

\begin{tabular}{llccc}
\hline \hline 1979-2006 & & Log Likelihood & AIC & Lag Length \\
\hline & NBR & 3553.75 & -20.50 & 13 \\
& CSM (M1) & 3995.40 & -22.82 & 17 \\
& CSM (M2) & 3631.02 & -20.58 & 17 \\
& CSM (M3) & 3585.73 & -20.31 & 17 \\
\cline { 2 - 5 } $1979-1982$ & & Log Likelihood & AIC & Lag Length \\
\hline & NBR & 477.56 & -18.40 & 2 \\
& CSM (M1) & 588.09 & -19.00 & 8 \\
& CSM (M2) & 412.63 & -16.36 & 1 \\
& CSM (M3) & 401.58 & -15.90 & 1 \\
\hline & & Log Likelihood & AIC & Lag Length \\
\hline & NBR & 3342.01 & -22.14 & 8 \\
& CSM (M1) & 3857.63 & -24.81 & 16 \\
& CSM (M2) & 3402.66 & -22.45 & 9 \\
& CSM (M3) & 3496.8 & -22.21 & 17 \\
\cline { 2 - 5 } & & Log Likelihood & AIC & Lag Length \\
\hline & NBR & 1791.88 & -24.05 & 2 \\
& CSM (M1) & 1982.47 & -26.88 & 1 \\
& CSM (M2) & 1848.38 & -25.05 & 1 \\
& CSM (M3) & 1810.42 & -24.53 & 1 \\
\hline \hline
\end{tabular}

\subsection{Alternative Monetary Aggregates and the Liquidity Puzzle}

We estimate $Z_{t}$ for each of four measures of the money stock. We use non-borrowed reserves as our benchmark model, because attempts to solve the liquidity puzzle have focused on narrowly defined monetary aggregates in general and non-borrowed reserves in particular (see Serletis and Chwee 1997). 
We calculate generalized impulse response functions as described by Pesaran and Shin (1998), who construct an orthogonal set of innovations that do not depend on the VAR ordering used. ${ }^{7}$ Figure 2 plots the accumulated response of the FEDF to a positive one-standard-deviation shock of the log change of various measures of the money stock. The confidence band is computed using asymptotic standard errors.
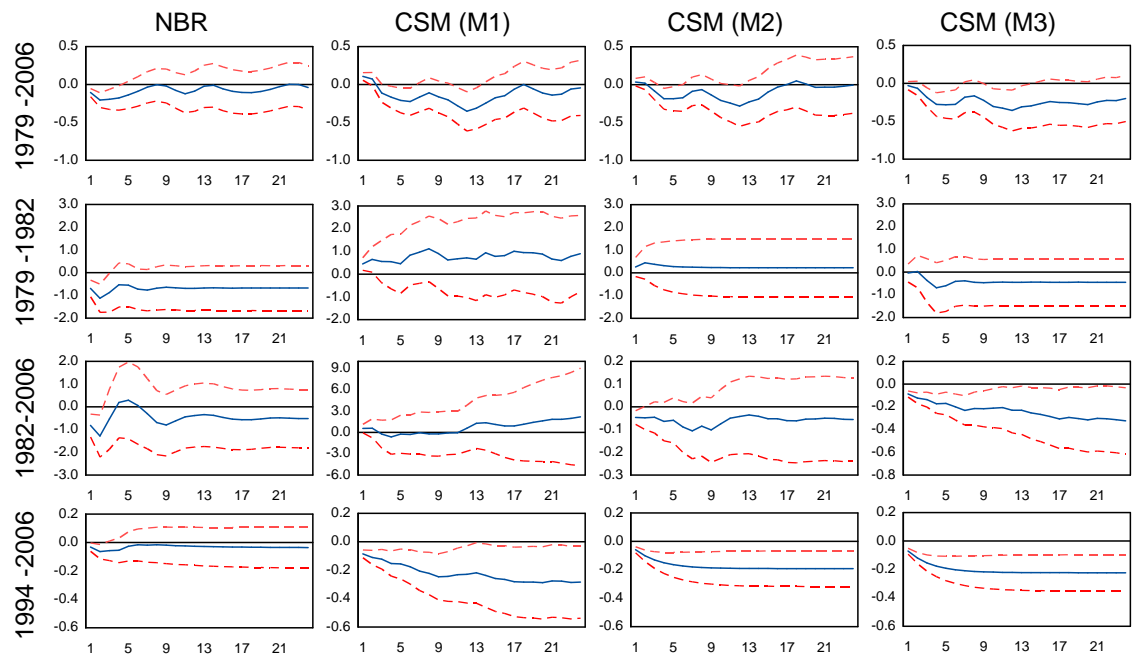

- Impulse Response Funcetion

95\% Confidence Interval

Figure 2: Accumulated impulse response of the FEDF to a positive one standard deviation shock of the log difference of various measures of the money stock, where NBR is non-borrowed reserves and CSM (M1), CSM (M2), CSM (M3) are the Current Stock of Money measured at the M1, M2 and M3 levels of aggregation. An orthogonal set of innovations that do not depend on the VAR ordering are used (Pesaran and Shin 1998). The confidence band is computed using asymptotic standard errors.

${ }^{7}$ We also tried several recursive orderings using a Cholesky decomposition. This did not significantly change our results. 
When non-borrowed reserves are used to measure the money stock, we find a negative correlation between an innovation in the money stock and the response of the FEDF. While the liquidity effect is statistically significant for about six months after the initial shock, the magnitude of the response is still quite small, only about $0.25 \%$. Results from the sub-periods are similar.

The CSM does not fare as well at the M1 or M2 levels of aggregation as at the M3 level. During the 1979 - 1982 sub-period, the response of CSM M1 and M2 to the FEDF is always positive, although never significant. During the 1982 - 2006 sub-period, CSM at the M2 level exhibits the liquidity effect, but it is statistically insignificant. During the 1994 - 2006 sub-period, however, we see strong, statistically significant liquidity effect exhibited at both M1 and M2 levels of aggregation. CSM at the M3 level of the aggregation exhibits liquidity effect during the full sample and in all sub-periods, although that effect is not significant during the 1979 - 1982 sub-period. With the exception of the $1979-$ 1982 sub-period, the CSM (M3) exhibits stronger and more persistent liquidity effect than does non-borrowed.

It might initially seem surprising that the broader aggregates exhibit stronger liquidity effect than the narrow aggregates, as the conventional wisdom has been to use narrow aggregates to fix the liquidity puzzle. However, given both the analysis in section 2.3.3 and aggregation theory, it is not unexpected that the properly weighted broader aggregates perform better. Traditional narrow money measures, such as non-borrowed reserves, arbitrarily discard 
information, ignoring the monetary services of monetary assets not included, while improperly weighted broad monetary aggregates severely distort the monetary service flow by failing to remove the investment motive which is greatest for the most distant substitutes for currency.

\subsection{Analysis of the Variance Decomposition of FEDF}

If traditional measures of narrow money are discarding relevant information about the monetary effect of assets not included in the aggregate, then we should see evidence in the variance decomposition of the FEDF. Given the analysis in section 4.2 , we would expect broader aggregates to explain a greater percentage of the variance of the FEDF. Figure 3 plots the percentage of variance of the first difference of the FEDF by various monetary variables. 

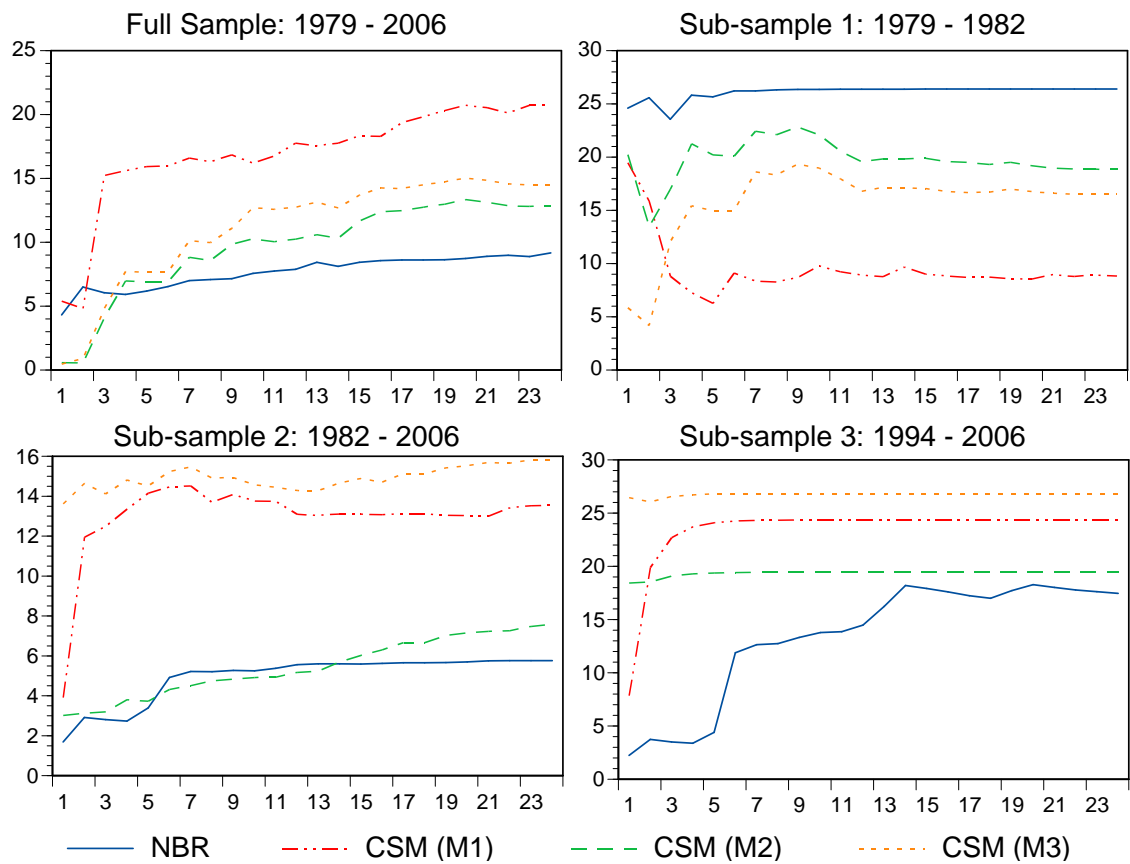

Figure 3: Percentage of variance of the first difference of the FEDF with various monetary variables. A separate VAR is estimated for each monetary aggregate and each sub-period. The variance decompositions were computed using the following Cholesky ordering: log difference of the money stock, FEDF, PCE, and IP.

For each VAR estimated, the variance decompositions of the log change of the FEDF were computed using the following Cholesky ordering: log difference of the money stock, FEDF, PCE, and IP. We tried various Cholesky orderings without significant variations in results. Our chosen ordering was selected to be consistent with Leeper and Gordon (1992).

During the full sample period, the CSM explains a greater proportion of the variance in the FEDF than does non-borrowed reserves at all levels of aggregation, and the CSM explains a greater proportion of the variance in the 
FEDF in all sub-periods except 1979 - 1982. In sub-periods after 1982, we saw that CSM (M3) explains the greatest proportion of the variance in the FEDF, as is consistent with the results from analysis of the impulse response functions.

\subsection{Further Discussion of Results}

Leeper and Gordon (1992) provide a summary of their result, which we find convenient to quote in order to place our results into context with theirs.

"The response of interest rates to a money growth innovation frequently becomes positive and is never negative when the correlations are conditioned on past interest rates money growth, prices and output.” (Leeper and Gordon, 1992)

We found that when CSM (M3) is used to measure the money stock, the response of the Federal Funds Rate is negative in our full sample and in all subperiods tested, and the negative response is significant in all but the $1979-1982$ sub-period.

"The signs and the patterns of the correlations between money growth and interest rates are not robust across sub-periods."

(Leeper and Gordon, 1992)

With the exception of NBR, we find similar inconsistency in the signs of the response of the federal funds rate across sub periods at lower levels of aggregation (M1 and M2). However that inconsistency vanishes when a properly measured and sufficiently broad aggregate is used. 
"When prices and output are also included in the unrestricted VAR, the correlation [between money stock innovations and the Federal Funds Rate] is positive, independent of the assumption about the exogeneity of money." (Leeper and Gordon, 1992)

In an unrestricted VAR including price and output, we found the response of the Federal Funds Rate to innovations of money stock was negative across subperiods for NBR and CSM (M3), but that response is stronger and remains significant for a longer period when CSM (M3) is used.

\section{Conclusion}

The traditional approach to solving the liquidity puzzle has been to use a narrowly defined monetary aggregate, such as non-borrowed reserves. Our results suggest that this may not be the best approach for two reasons. (1) We see from aggregation theory that the simple sum methodologies employed in the official monetary aggregates, published by the Federal Reserve and many other central banks, confound the monetary and investment stocks of money, thereby confounding substitution and income effects of interest rate changes. This confounding masks the relationship between the money stock and interest rates.

(2) Traditional narrow money measures, such as non-borrowed reserves, arbitrarily discard information, ignoring the monetary effects of monetary assets not included in the aggregate. 
We found that when measured using a reputable index number, the broadest monetary aggregate exhibits stronger liquidity effects than the more narrow measures. This is contrary to the current literature. We also found from the variance decompositions analysis that the properly-weighted broader aggregates typically contain more explanatory information than the narrow aggregates about the movements of the FEDF. 


\section{References}

Anderson, Richard G., and Robert H. Rasche. 2000. Retail sweep programs and bank reserves, 1994--1999. Federal Reserve Bank of St. Louis.

Arrow, K J, and G H Hahn. 1971. General Competitive Analysis: San Francisco: Holden-Day.

Barnett, William A. 1980. Economic Monetary Aggregates: An Application of Index Number and Aggregation Theory. Journal of Econometrics 14: 11-48. Reprinted in The Theory of Monetary Aggregation, William Barnett and Apostolos Serletis (eds.), 2000, Amsterdam: Elsevier, 1148.

1991. A Reply to Julio J. Rotemberg. In: Belongia, M. T. (Ed.), Monetary Policy on the 75th Anniversary of the Federal Reserve System. Proceedings of the Fourteenth Annual Economic Policy Conference of the Federal Reserve Bank of St. Louis, Kluwer, pp. 189222. Reprinted in The Theory of Monetary Aggregation, William Barnett and Apostolos Serletis (eds.), 2000, Amsterdam: Elsevier, 296306.

1995. Exact Aggregation Under Risk. In: Barnett, W. A., Salles,M., Moulin, H., Schoeld, N. (Eds.), Social Choice, Welfare and Ethics. Proceedings of the Eighth International Symposium in Economic Theory and Econometrics, Cambridge University Press, pp. 353-374. Reprinted in The Theory of Monetary Aggregation, William Barnett and Apostolos Serletis (eds.), 2000, Amsterdam: Elsevier, 195-216. 
Barnett, William A, Yi Liu, and Mark Jensen. 1997. CAPM Risk Adjustment for

Exact Aggregation Over Financial Assets. Macroeconomic Dynamics 1

(2):485-512. Reprinted in The Theory of Monetary Aggregation,

William Barnett and Apostolos Serletis (eds.), 2000, Amsterdam:

Elsevier, 245-273.

Barnett, William A., Unja Chae, and John W. Keating. 2005. The Discounted

Economic Stock of Money with VAR Forecasting. Annals of Finance 2

(2):229-258.

Barnett, William A., and Marcelle Chauvet. 2009. How Better Monetary

Statistics Could Have Signaled the Systemic Risk Precipitating the

Financial Crisis. Journal of Econometrics, forthcoming.

Barnett, William A., John Keating, and Logan J. Kelly. 2008. Toward a Bias

Corrected Currency Equivalent Index. Economics Letters 100:448-451.

Barnett, William A., and Apostolos Serletis, eds. 2000. The theory of monetary

aggregation. Contributions to Economic Analysis, vol. 245:

Amsterdam: Elsevier.

Bernanke, Ben S., Jean Boivin, and Piotr Eliasz. 2005. Measuring the Effects of Monetary Policy: A Factor-Augmented Vector Autoregressive

(FAVAR) Approach. Quarterly Journal of Economics 120 (1):387 -

422.

Christiano, Lawrence J. 1991. Modeling the Liquidity Effect of a Money Shock. Federal Reserve Bank of Minneapolis Quarterly Review 15 (1):3 - 34.

Christiano, Lawrence J., Martin Eichenbaum, and Charles Evans. 1996. The Effects of Monetary Policy Shocks: Evidence from the Flow of Funds. Review of Economics and Statistics 78 (1):16 - 34. 
Cochrane, John H. 1989. The Return of the Liquidity Effect: A Study of the Short-run Relation between Money Growth and Interest Rates. Journal of Business and Economic Statistics 7 (1):75 - 83.

Dutkowsky, Donald H., and Barry Z. Cynamon. 2003. Sweep Programs: The Fall of M1 and Rebirth of the Medium of Exchange. Journal of Money, Credit, and Banking 35 (2):263 - 279.

Eichenbaum, Martin, and Charles L. Evans. 1995. Some Empirical Evidence on the Effects of Shocks to Monetary Policy on Exchange Rates. Quarterly Journal of Economics 110 (4):975 - 1009.

Hamilton, James D. 1997. Measuring the Liquidity Effect. American Economic Review 87 (1):80 - 97.

Hutt, William H. 1963. Keynesianism - Retrospect and Prospect: Chicago: Regnery.

Keen, Benjamin D. 2004. In search of the liquidity effect in a modern monetary model. Journal of Monetary Economics 51 (7):1467-1494.

Kelly, Logan J. 2009. The Stock of Money and Why You should Care. Advances in Econometrics: Measurement Error - Econometrics and Practice. Volume 24. Jane Binner, David Edgerton, and Thomas Elger (Eds.).

- 2010. The Current Stock of Money: An Aggregation Theoretic Measure of Narrowly Defined Money. Applied Economics Letters. Forthcoming.

Leeper, Eric M., and David B. Gordon. 1992. In Search of the Liquidity Effect. Journal of Monetary Economics 29 (3):341 - 369.

Litterman, Robert B., and Laurence M. Weiss. 1985. Money, Real Interest Rates, and Output: A Reinterpretation of Postwar U.S. Data. Econometrica 53: 129-156. 
Melvin, Michael. 1983. The Vanishing Liquidity Effect of Money on Interest: Analysis and Implications for Policy. Economic Inquiry 21 (2):188 202.

Mishkin, Frederic S. 1982. Monetary Policy and Short-Term Interest Rates: An Efficient Markets-Rational Expectations Approach. Journal of Finance 37 (1):63-72.

Pesaran, H. Hashem, and Yongcheol Shin. 1998. Generalized impulse response analysis in linear multivariate models. Economics Letters 58 (1):17-29.

Reichenstein, William. 1987. The Impact of Money on Short-term Interest Rates. Economic Inquiry 25 (1):67-82.

Rotemberg, Julio J, John C Driscoll, and James M Poterba. 1995. Money, Output, and Prices: Evidence from a New Monetary Aggregate. Journal of Business and Economic Statistics 13 (1):67-83.

Serletis, Apostolos, and Victor Chwee. 1997. Resolving the Liquidity Puzzle. Macroeconomic Dynamics 1 (4):720 - 739.

Sims, Christopher A. 1980. Comparison of Interwar and Postwar Business Cycles: Monetarism Reconsidered. American Economic Review 70 (2):250 - 257.

1992. Interpreting the Macroeconomic Time Series Facts: The Effects of Monetary Policy. European Economic Review 36 (5):975 - 1000.

Strongin, Steven. 1995. The Identification of Monetary Policy Disturbances: Explaining the Liquidity Puzzle. Journal of Monetary Economics 35 (3):463 - 497. 